\title{
Lobectomy leads to optimal survival in early-stage small cell lung cancer: A retrospective analysis
}

\author{
John M. Varlotto, MD, ${ }^{\mathrm{a}}$ Abram Recht, MD, ${ }^{\mathrm{b}}$ John C. Flickinger, MD, ${ }^{\mathrm{c}}$ Laura N. Medford-Davis, BA, ${ }^{\mathrm{d}}$ \\ Anne-Marie Dyer, MS, ${ }^{e}$ and Malcolm M. DeCamp, MD $^{\mathrm{f}}$
}

\begin{abstract}
Objective: Stage I or II small cell lung cancer is rare. We evaluated the contemporary incidence of early-stage small cell lung cancer and defined its optimal local therapy.
\end{abstract}

\begin{abstract}
Methods: We analyzed the incidence, treatment patterns, and outcomes of 2214 patients with early-stage small cell lung cancer (1690 with stage I and 524 with stage II) identified from the Surveillance, Epidemiology, and End Results database from 1988 to 2005.
\end{abstract}

\begin{abstract}
Results: Early-stage small cell lung cancer constituted a stable proportion of all small cell lung cancers $(3 \%-$ $5 \%)$, lung cancers $(0.10 \%-0.17 \%)$, and stage I lung cancers $(1 \%-1.5 \%)$ until 2003 but, by 2005 , increased significantly to $7 \%, 0.29 \%$, and $2.2 \%$, respectively $(P<.0001)$. Surgery for early-stage small cell lung cancer peaked at $47 \%$ in 1990 but declined to $16 \%$ by 2005 . Patients treated with lobectomy or greater resections (lobe) without radiotherapy had longer median survival (50 months) than those treated with sublobar resections (sublobe) without radiotherapy (30 months, $P=.006$ ) or those treated with radiotherapy alone (20 months, $P<.0001)$. Patients undergoing sublobe without radiotherapy also demonstrated superior survival than patients receiving radiotherapy alone $(P=.002)$. The use or omission of radiotherapy made no difference after limited resection (30 vs 28 months, $P=.6$ ). Multivariable analysis found survival independently related to age, year of diagnosis, tumor size, stage, and treatment (lobe vs sublobe vs radiotherapy alone).
\end{abstract}

Conclusions: Surgery is an underused modality in the management of early-stage small cell lung cancer. Lobectomy provides optimal local control and leads to superior survival. Although sublobar resection proved inferior to lobectomy, it conferred a survival advantage superior to radiotherapy alone. The addition of radiotherapy to resection provided no additional benefit. (J Thorac Cardiovasc Surg 2011;142:538-46)

Before the 1970s, surgical resection was often used to treat localized early-stage small cell lung cancer (SCLC). ${ }^{1}$ However, in 1973, the Medical Research Council published the only prospective, randomized trial comparing resection with radiotherapy (RT). ${ }^{2}$ This demonstrated that definitive RT yielded a higher survival than surgery and thus established RT as the procedure of choice. However, this trial was conducted before modern pathologic assessment, ${ }^{3}$ the establishment of platinum-based chemotherapy, ${ }^{4}$ and the development of modern surgical and radiotherapeutic techniques. In contrast, the current National Comprehensive

From the Division of Radiation Oncology, ${ }^{a}$ Pennsylvania State University, Hershey, $\mathrm{Pa}$; Department of Radiation Oncology, ${ }^{\mathrm{b}}$ Beth Israel Deaconess Medical Center, Boston, Mass; Department of Radiation Oncology, ${ }^{\mathrm{c}}$ Pittsburgh Cancer Institute, Pittsburgh, Pa; Harvard Medical School, ${ }^{\text {d }}$ Boston, Mass; Department of Public Health Sciences, ${ }^{\mathrm{e}}$ Pennsylvania State University, Hershey, Pa; and Division of Thoracic Surgery, ${ }^{\mathrm{f}}$ Northwestern Memorial Hospital, Chicago, Ill.

Disclosures: Authors have nothing to disclose with regard to commercial support.

Read at the 90th Annual Meeting of The American Association for Thoracic Surgery, Toronto, Ontario, Canada, May 1-5, 2010.

Received for publication May 1, 2010; revisions received Oct 15, 2010; accepted for publication Nov 2, 2010; available ahead of print June 20, 2011.

Address for reprints: Malcolm M. DeCamp, MD, Fowler-McCormick Professor of Surgery, Northwestern University Feinberg School of Medicine, Chief, Division of Thoracic Surgery, Northwestern Memorial Hospital, 676 N St Clair, Suite 650, Chicago, IL 60611 (E-mail: mdecamp@nmh.org).

$0022-5223 / \$ 36.00$

Copyright (c) 2011 by The American Association for Thoracic Surgery doi:10.1016/j.jtcvs.2010.11.062
Cancer Network guidelines recommend either lobectomy (preferred) and mediastinal node sampling or dissection, or concurrent chemotherapy and RT for all patients who have clinical T1-2N0 presentations of SCLC with negative mediastinoscopy or mediastinal staging. ${ }^{5}$ This guideline is considered to be in category $2 \mathrm{~A}$, meaning that it is based on lower-level evidence, but there is uniform consensus among the guideline participants.

Because early-stage SCLC is a rare presentation of lung cancer, prospective, randomized trials comparing local treatment modalities are unlikely to be performed. Therefore, the main purpose of our retrospective investigation was to compare results with surgery alone, RT alone, and combined surgery and RT on survival. In addition, we investigated the frequency of early-stage SCLC as a percentage of all SCLCs, all lung cancers, and all stage I lung cancers. Finally, because some physicians are treating patients with unbiopsied but suspicious lung masses with stereotactic body RT, we compared the presenting characteristics of patients with resected stage I SCLC with those of resected stage I non-small cell lung cancer (NSCLC). ${ }^{6-9}$

\section{PATIENTS AND METHODS}

Data were obtained from the Surveillance, Epidemiology, and End Results (SEER) program of the US National Cancer Institute. The SEER-17 database includes patients with diagnoses made between 1988 and 2005, 


$$
\begin{aligned}
& \text { Abbreviations and Acronyms } \\
& \begin{aligned}
\text { CI } & =\text { confidence interval } \\
\text { HR } & =\text { hazard ratio } \\
\text { LCSS } & =\text { lung cancer-specific survival } \\
\text { NOS } & \text { not otherwise specified } \\
\text { NSCLC } & =\text { non-small cell lung cancer } \\
\text { RT } & =\text { radiotherapy } \\
\text { SCLC } & =\text { small cell lung cancer } \\
\text { SEER } & =\text { Surveillance, Epidemiology, and End } \\
& \text { Results }
\end{aligned}
\end{aligned}
$$

and is derived from a set of geographically defined, population-based cancer registries operated under direct contract with the National Cancer Institute by local nonprofit organizations in Connecticut, Iowa, Hawaii, New Mexico, Utah, Atlanta, Detroit, Los Angeles, San Francisco-Oakland, San Jose-Monterey, Seattle-Puget Sound, Rural Georgia, Kentucky, Louisiana, and New Jersey, and among Arizona Indians and Alaskan Native populations. ${ }^{10}$ The case ascertainment rate from the SEER registries has been reported to be $97.5 \%$ and is thought to be generally representative of the entire American population. ${ }^{11}$ Data were accessed on February 3, 2009. Because we used existing data that did not identify individual subjects, informed consent by the study participants was not necessary. Patients with less than 3 months of follow-up were excluded.

Patients with a stage I or II SCLC diagnosis, defined according to the American Joint Committee on Cancer, ${ }^{12}$ were selected for this analysis. Histologic types identified as SCLC including combined small cell and fusiform cell carcinomas were used for analysis. The following histologic types were defined as NSCLC: NSCLC not otherwise specified (NOS, which included undifferentiated carcinoma NOS and anaplastic carcinoma NOS); large cell carcinoma (large cell neuroendocrine carcinoma, large cell carcinoma with rhabdoid phenotype, lymphoepithelioma-like carcinoma, basaloid carcinoma, and clear cell carcinoma); adenocarcinoma (including acinar cell carcinoma, mixed subtype adenocarcinoma, alveolar adenocarcinoma, bronchioloalveolar carcinoma, non-mucinous bronchioloalveolar carcinoma, mucinous bronchioloalveolar carcinoma, mixed mucinous and non-mucinous bronchioloalveolar carcinoma, clear cell adenocarcinoma, mucinous cystadenocarcinoma, mucinous or colloid adenocarcinoma, mucin-producing adenocarcinoma, papillary adenocarcinoma, signet ring adenocarcinoma, solid adenocarcinoma, well-differentiated fetal adenocarcinoma); adenosquamous carcinoma; and squamous cell carcinoma (basaloid squamous cell carcinoma, papillary squamous cell carcinoma, clear cell squamous cell carcinoma, keratinizing squamous cell carcinoma, large cell non-keratinizing squamous cell carcinoma, and small cell non-keratinizing squamous cell carcinoma). Surgery was characterized as lobe (lobectomy, bilobectomy, pneumonectomy, or extended pneumonectomy) or sublobe (wedge or segmental resection).

To compare presenting characteristics of stage I SCLC and stage I NSCLC, data for both histologic subtypes were obtained for patients who underwent a definitive surgical procedure and were analyzed using chi-square and Wilcoxon rank-sum tests. Characteristics analyzed included age, sex, race (white, black, other), tumor location (left lower, left upper, right lower, right middle, and right upper lobes, and mainstem bronchus locations), and tumor size.

Unadjusted, stratified analyses were performed to compare survival for sublobe without RT versus lobe without RT, sublobe without RT versus RT only, lobe without RT versus RT only, sublobe without RT versus sublobe with RT, and lobe without RT versus sublobe with RT. The log-rank test was used to test for differences in survival among the various treatments. ${ }^{13}$ All survival curves were generated using the Kaplan-Meier method. ${ }^{14}$
To assess the effect of treatment on survival while controlling for other factors, a multivariable proportional hazards model was performed. Treatment was analyzed as a categoric variable, with categories representing the various combinations of surgery with and without RT (sublobe without RT, sublobe with RT, lobe without RT, lobe with RT), in addition to a separate category for RT only. Patients without surgery or radiation were excluded from the analysis. The following covariates were also included: year of diagnosis, patient age, race, gender, tumor stage, tumor location, nodes examined (none, $1-5, \geq 6$, unknown), and size.

\section{RESULTS}

There were 2214 patients identified with early-stage SCLC and more than 3 months of follow-up. The median survival time was 20 months for the entire group. The distribution of patient and histopathologic characteristics by treatment are described in Table 1. The percentage of stage I and II SCLC among all SCLCs (Figure 1, A) remained relatively stable between 1988 and 2003 (range, 3.00\%$4.96 \%$ ), but increased dramatically in 2004 and 2005 $(6.86 \%$ and $7.48 \%, P<.0001)$. Likewise, the percentage of stage I and II SCLCs among all lung cancers (Figure 1, $A)$ and the percentage of stage I SCLCs among all stage I lung cancers (Figure 1, $B$ ) remained stable during the years 1988 to 2003 (ranges, $0.10 \%-0.17 \%$ and $0.73 \%-1.51 \%$, respectively), but also increased greatly during the years 2004 and $2005(0.28 \%$ and $0.29 \%$, and $2.11 \%$ and $2.22 \%$, respectively; $P<.0001$ ).

The median survival time for patients with stage I SCLC treated with lobectomy without RT (50 months) was significantly greater than that for patients treated with sublobar resection without RT (30 months, $P=.006$ ) and those treated with RT alone $(20$ months, $P<.0001)$. The median overall survival time was also significantly longer for patients treated by sublobar resection without RT than for patients who received RT alone $(P=.002)$. The 2-, 3-, and 5-year actuarial overall survivals for patients undergoing lobectomy without RT were $65.2 \%, 58.6 \%$, and $47.4 \%$, respectively, compared with $62.5 \%, 41.7 \%$, and $28.5 \%$, respectively, for those undergoing sublobar resection without RT and $39.6 \%, 28.3 \%$, and $17.2 \%$, respectively, for patients treated by RT alone (Figure 2, $A$ ). Likewise, patients treated by lobectomy without RT had a greater median lung cancer-specific survival (LCSS) (89 months) than those treated with sublobar resection without RT (35 months, $P=.037)$ or those treated with RT alone (24 months, $P<.0001$ ), as shown in Figure 2, $B$.

When lobectomy or greater was performed, the use of adjuvant RT was associated with a shorter but not significantly different median survival time (50 vs 37 months, $P=.201$ ). The overall survival and LCSS also did not differ for these groups (Figure 3, $A, B$ ). No difference in the median overall survival time was found with the use of adjuvant RT when sublobar resection was performed (30 vs 28 months, $P=.585$ ) or in overall survival of LCSS rates (Figure 3, $C, D)$. 
TABLE 1. Patient-related and histopathologic factors

\begin{tabular}{|c|c|c|c|c|c|}
\hline & $\begin{array}{l}\text { All patients } \\
(\mathrm{n}=\mathbf{2 2 1 4})\end{array}$ & $\begin{array}{l}\text { No treatment* } \\
\quad(\mathbf{n}=\mathbf{5 5 8})\end{array}$ & $\begin{array}{l}\text { Surgery only } \\
\quad(n=436)\end{array}$ & $\begin{array}{l}\text { Radiation only } \\
\qquad(\mathbf{n}=936)\end{array}$ & $\begin{array}{l}\text { Surgery and radiation } \\
\qquad(\mathrm{n}=148)\end{array}$ \\
\hline \multicolumn{6}{|l|}{ Gender } \\
\hline Female & $1144(52)$ & $293(53)$ & $216(50)$ & $490(52)$ & $74(50)$ \\
\hline Male & $1070(48)$ & $265(47)$ & $220(50)$ & $446(48)$ & $74(50)$ \\
\hline \multicolumn{6}{|l|}{ Age } \\
\hline $20-49$ y & $100(5)$ & $12(2)$ & $15(3)$ & $55(6)$ & $11(7)$ \\
\hline $50-59$ y & $324(15)$ & $63(11)$ & $60(14)$ & $150(16)$ & $29(20)$ \\
\hline $60-69 y$ & $693(31)$ & $146(26)$ & $147(34)$ & $296(32)$ & $58(39)$ \\
\hline $70-79 y$ & $861(39)$ & $256(46)$ & $184(42)$ & $324(35)$ & $48(32)$ \\
\hline $80+y$ & $236(11)$ & $81(15)$ & $30(7)$ & $111(12)$ & $2(1)$ \\
\hline \multicolumn{6}{|l|}{ Race } \\
\hline White & $1910(86)$ & $465(83)$ & $395(91)$ & $798(85)$ & $128(87)$ \\
\hline Black & $190(9)$ & $66(12)$ & $25(6)$ & $80(9)$ & $10(7)$ \\
\hline Other & $112(5)$ & $27(5)$ & $16(4)$ & $57(6)$ & $9(6)$ \\
\hline \multicolumn{6}{|l|}{ Stage } \\
\hline I & $1690(76)$ & $445(80)$ & $361(83)$ & $692(74)$ & $87(59)$ \\
\hline II & $524(24)$ & $113(20)$ & 75 (17) & $244(26)$ & $61(41)$ \\
\hline \multicolumn{6}{|l|}{ Grade } \\
\hline I-II & $31(1)$ & $6(1)$ & $16(4)$ & $4(0.4)$ & $5(3)$ \\
\hline III & $252(11)$ & $45(8)$ & $94(22)$ & $69(7)$ & $32(22)$ \\
\hline IV & $939(42)$ & $236(42)$ & $187(43)$ & 398 (43) & $58(39)$ \\
\hline Unknown & $992(45)$ & $271(49)$ & $139(32)$ & $465(50)$ & $53(36)$ \\
\hline \multicolumn{6}{|l|}{ Location } \\
\hline Lower left & $344(16)$ & $90(17)$ & $57(13)$ & $136(15)$ & $37(26)$ \\
\hline Upper left & $573(27)$ & $136(26)$ & $127(30)$ & $240(27)$ & $36(25)$ \\
\hline Middle bronchus & $137(7)$ & $41(8)$ & $0(0)$ & $83(9)$ & $2(1)$ \\
\hline Lower right & $325(15)$ & $77(15)$ & $81(19)$ & 139 (16) & $13(9)$ \\
\hline Middle right & $132(6)$ & $31(6)$ & $27(6)$ & $57(6)$ & $11(8)$ \\
\hline Upper right & $593(28)$ & $145(28)$ & $137(32)$ & $232(26)$ & $46(32)$ \\
\hline \multicolumn{6}{|l|}{ No. of nodes examined } \\
\hline None & $1641(74)$ & $531(95)$ & $90(21)$ & $901(96)$ & $31(21)$ \\
\hline $1-5$ & $242(11)$ & $10(2)$ & $134(31)$ & $17(2)$ & $57(39)$ \\
\hline $6+$ & $199(9)$ & $6(1)$ & $144(33)$ & $2(0.2)$ & $37(25)$ \\
\hline Unknown & $132(6)$ & $11(2)$ & $68(16)$ & $16(2)$ & $23(16)$ \\
\hline \multicolumn{6}{|l|}{ No. of positive nodes } \\
\hline 0 & 409 (19) & $17(3)$ & $277(65)$ & $21(2)$ & $58(41)$ \\
\hline $1+$ & $139(6)$ & $9(2)$ & $61(14)$ & $9(1)$ & $52(37)$ \\
\hline None examined & $1641(75)$ & $531(95)$ & $90(21)$ & $901(97)$ & $31(22)$ \\
\hline Tumor size & $30.0(0-210)$ & $30.0(0-210)$ & $23.0(3-110)$ & $35.0(0-150)$ & $21.5(4-130)$ \\
\hline \multicolumn{6}{|l|}{ Type of surgical resection } \\
\hline Less than lobectomy & $167(8)$ & & $117(27)$ & & $46(31)$ \\
\hline Lobectomy/bilobectomy & 412 (19) & & $304(70)$ & & $92(62)$ \\
\hline Pneumonectomy & $28(1)$ & & $15(3)$ & & $10(7)$ \\
\hline
\end{tabular}

*Includes tumor that underwent biopsies, laser ablation, or local cautery.

Results of the multivariable proportional hazards model are shown in Table 2. Characteristics significantly associated with overall survival were year of diagnosis (hazard ratio $[\mathrm{HR}]=0.98 ; 95 \%$ confidence interval $[\mathrm{CI}], 0.97-0.998$; $P=.029)$, age $(\mathrm{HR}=1.19 ; 95 \% \mathrm{CI}, 1.14-1.24 ; P<.0001)$, stage II (HR $=1.48 ; 95 \% \mathrm{CI}, 1.26-1.74 ; P<.0001)$, tumor size $(\mathrm{HR}=1.01 ; 95 \% \mathrm{CI}, 1.001-1.01 ; P=.014)$, lobe without RT versus RT only $(\mathrm{HR}=0.56$; $95 \% \mathrm{CI}, 0.41-0.76$; $P<.001)$, and lobe without RT versus sublobe without RT $(\mathrm{HR}=0.73 ; 95 \% \mathrm{CI}, 0.53-0.999 ; P=.049)$.
Trends in the use of the various local therapeutic options can be seen in Figure 4. The use of RT only was at its lowest, $18 \%$, in 1990 , but increased to $46 \%$ of all treatments in 1991 and subsequently ranged from $35.7 \%$ to $50.0 \%$. During the new century, the use of RT only remained at $44.2 \%$ to $50.0 \%$. No local treatment was at its lowest use in 1991 at $16.0 \%$, but since 1990 its use has fluctuated from $19.8 \%$ to $34.3 \%$. The use of surgery only peaked in 1990 at $47.4 \%$ of all local treatments, but its use decreased greatly during the 1990s (range, $18.2 \%-29.7 \%$ ) and in the new century (range, 

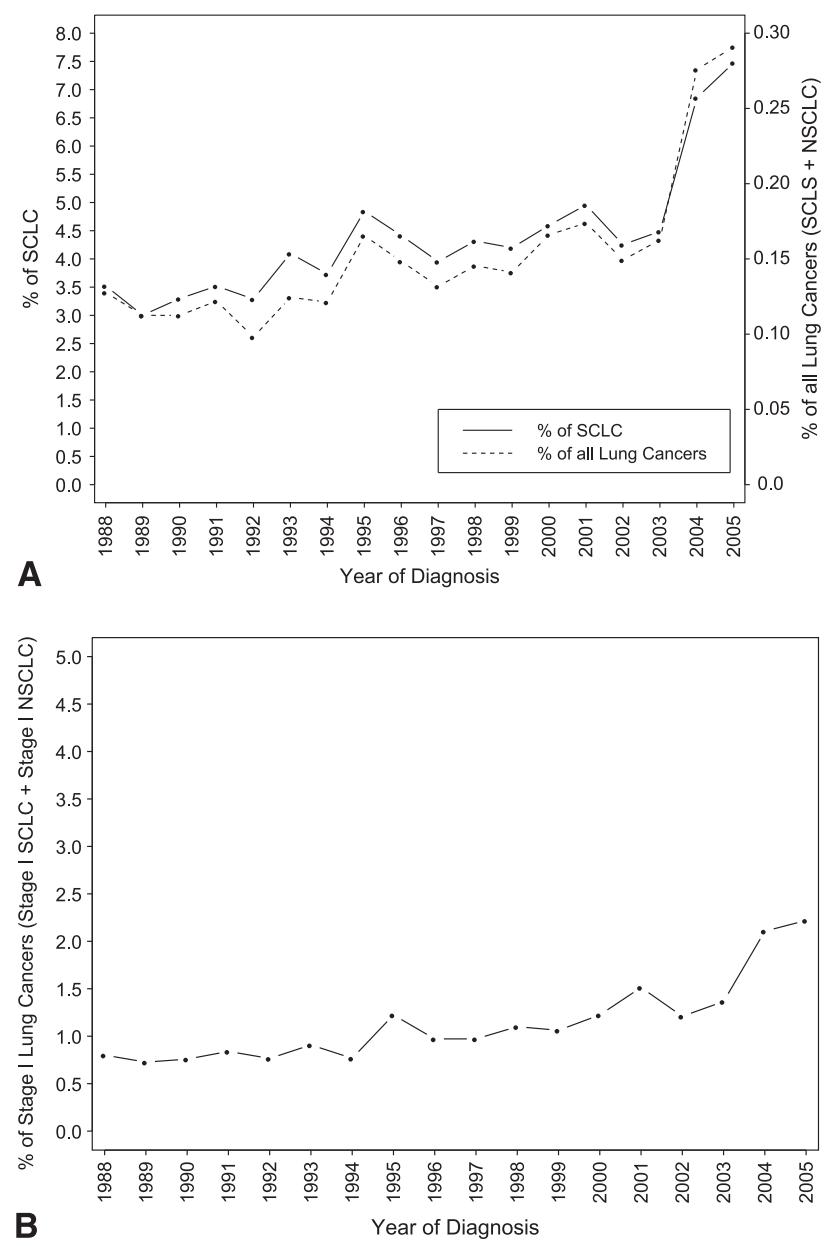

FIGURE 1. A, Frequency of stage I/II SCLC as a percentage of all SCLCs and as a percentage of all lung cancers (NSCLC and SCLC). B, Frequency of stage I SCLC as a percentage of all stage I lung cancers. NSCLC, Non-small cell lung cancer; $S C L C$, small cell lung cancer.

$16.0 \%-19.6 \%$ ). The use of both surgery and RT remained relatively uncommon and ranged from $1.4 \%$ to $13.6 \%$ of all local treatment options, peaking in 1999 at $13.6 \%$.

When patients treated with surgical resection for stage I SCLC were compared with those identified in SEER as having surgical therapy for stage I NSCLC, there were no differences in patient age, gender, race, or tumor location (data not shown). SCLC tumors were numerically but not statistically smaller in size.

\section{DISCUSSION}

The National Comprehensive Cancer Network Guidelines currently recommend either surgery (lobectomy preferable) or chemotherapy and concurrent RT for patients with good-performance status with clinical T1-2 N0 SCLCs. However, because of the rarity of this early presentation, there are scant data on which local modality to consider and even the type of surgical resection (ie, lobectomy
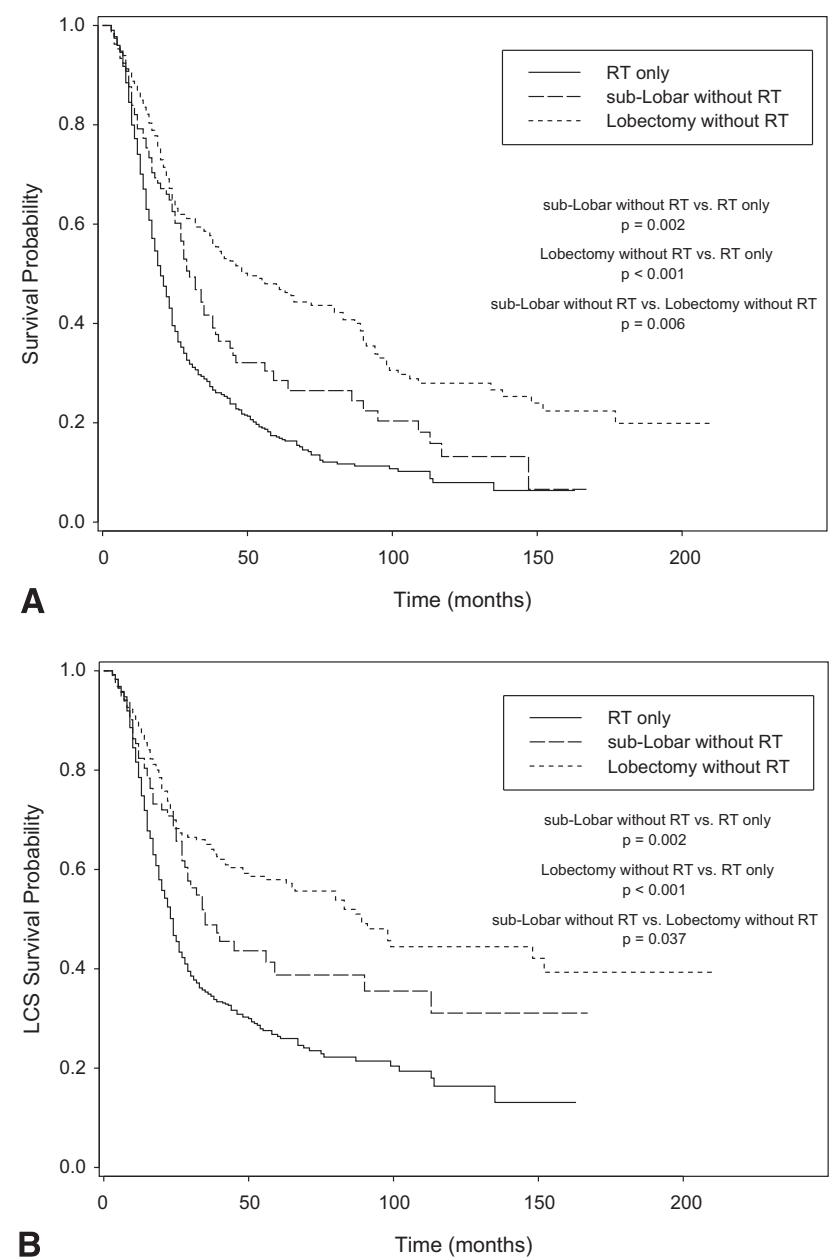

FIGURE 2. A, Actuarial survivals for patients treated with RT only, sublobar resection without RT, and lobectomy without RT. B, Actuarial LCSS for patients treated with RT only, sublobar resection without RT, and lobectomy without RT. $L C S$, Lung cancer-specific; $R T$, radiotherapy.

vs sublobar resection). Although early-stage SCLC remains rare, our investigation has shown that this presentation significantly increased during 2004 and 2005 and now comprises more than $7 \%$ of all small cell carcinomas. Moreover, stage I SCLC now constitutes more than $2 \%$ of all stage I lung cancers. To the best of our knowledge, there are no prospective or retrospective data comparing outcomes of different local treatment modalities to help guide therapeutic decisions. As shown in a previous prospective, randomized trial, which investigated the benefit of surgical resection in addition to chemotherapy and $\mathrm{RT},{ }^{15}$ our analysis similarly revealed that there was no survival benefit for patients to receive 2 local treatment modalities (radiation in addition to surgical resection).

Patients who were treated with RT as their sole local treatment modality were likely understaged. Ninety-seven percent of patients received only clinical staging and did not have any lymph nodes examined, compared with $21 \%$ 

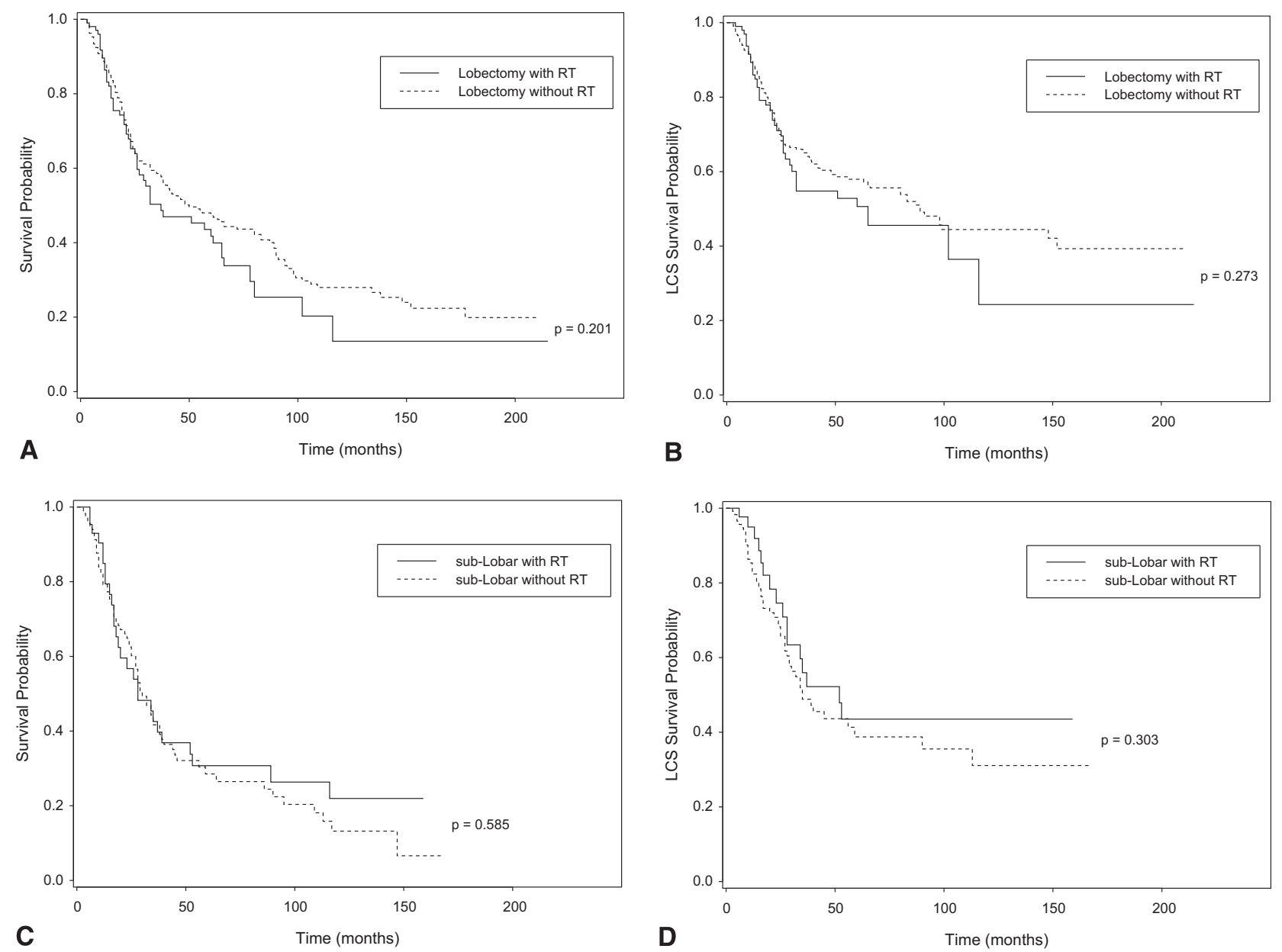

FIGURE 3. A, Actuarial survivals for patients treated with lobectomy with and without RT. B, Actuarial LCSS for patients treated with lobectomy with and without RT. C, Actuarial survivals for patients treated with sublobar resection with and without RT. D, Actuarial LCSS for patients treated with sublobar resection with and without RT. $L C S$, Lung cancer-specific; $R T$, radiotherapy.

of patients treated with surgery only and $22 \%$ of patients receiving both surgery and RT. Because the routine use of positron emission tomography as a staging tool was only practiced in the most recent 5-year time frame of this 17 -year retrospective analysis, a survival comparison of resection versus RT alone must be interpreted with extreme caution. Such a staging bias was emphasized by the International Association for the Study of Lung Cancer International Staging Committee in their recent report documenting a $20 \%$ to $25 \%$ rate of upstaging when patients with clinically staged SCLC underwent resection with nodal evaluation. ${ }^{16}$ In view of these considerations, a multivariable analysis (which controlled for the number of lymph nodes examined) revealed that lobectomy without RT was associated with a significant survival benefit compared with RT alone ( $P=.0002$, HR 0.559).

Lobectomy is the standard of care for resection of pathologic stage I NSCLC, providing superior survival and a lower risk of local recurrence than segmentectomy or wedge resection. ${ }^{17}$ Likewise, although retrospectively, our analysis revealed lobectomy (or greater if indicated) led to superior overall and cancer-specific survival and remains the surgical procedure of choice over sublobar resections for node-negative SCLC.

Despite the compelling argument in favor of surgery for stage I SCLC, $42 \%$ of patients in this retrospective analysis received RT as their sole local treatment modality. It is unfortunate that SEER-17 does not contain information on important radiation parameters, such as field size, radiation dose, intent of treatment, 3-dimensional versus 2-dimensional treatment planning, and fractionation schedule. With more advanced small cell presentations, hyperfractionated, accelerated treatment results in superior response rates and survival than does conventional fractionation. ${ }^{18}$ Whether this is true for early-stage SCLC is not currently known.

The multivariable analysis also demonstrated that survival depended on year of diagnosis, patient age, stage, and tumor size. The recent International Association for 
TABLE 2. Multivariable analysis for $S$ with radiotherapy \pm surgery as covariate (excluding patients treated with neither surgery nor radiotherapy)

\begin{tabular}{lcc}
\hline & Hazard ratio $(\mathbf{9 5} \% \mathbf{C I})$ & $\boldsymbol{P}$ value \\
\hline Year of diagnosis & $0.982(0.966-0.998)$ & .029 \\
Age & $1.189(1.144-1.236)$ & $<.0001$ \\
Race & Reference & .231 \\
White & $1.249(0.968-1.612)$ & \\
Black & $1.002(0.748-1.343)$ & .088 \\
Other & $1.040(0.907-1.193)$ & .988 \\
Male & & .576 \\
Tumor location & $0.970(0.787-1.195)$ & .067 \\
Left lower & $0.810(0.676-0.970)$ & .773 \\
Left upper & $1.020(0.735-1.414)$ & .022 \\
Mainstem bronchus & $0.759(0.614-0.940)$ & .907 \\
Right lower & $0.909(0.678-1.218)$ & .011 \\
Right middle & Reference & .522 \\
Right upper & $1.479(1.259-1.737)$ & $<.0001$ \\
Stage II & Reference & .634 \\
Nodes examined & $0.912(0.686-1.213)$ & .527 \\
0 & $0.844(0.597-1.193)$ & .336 \\
1-5 & $0.796(0.557-1.140)$ & .213 \\
$\geq 6$ & $1.005(1.001-1.008)$ & .014 \\
Unknown & Reference & .009 \\
Tumor size & $0.771(0.582-1.022)$ & .071 \\
Treatment & $0.745(0.490-1.133)$ & .168 \\
RT only & $0.559(0.410-0.763)$ & $<.001$ \\
L- without RT & $0.683(0.466-1.002)$ & .051 \\
L- with RT & & \\
L+ without RT & L+ with RT &
\end{tabular}

$C I$, Confidence interval; $R T$, radiotherapy

the Study of Lung Cancer Staging Project has identified that survival was directly correlated to both $\mathrm{T}$ and $\mathrm{N}$ descriptors. ${ }^{19}$ Lally and colleagues ${ }^{20}$ found older age, male gender, era of diagnosis, and African American race were independent predictors of hazard for mortality when limited-stage SCLC cases from SEER were reviewed. These cases included N0, N1, and N2 disease, and the analysis did not consider surgery as a therapeutic modality. ${ }^{20}$ Schreiber and colleagues ${ }^{21}$ recently used SEER to identify 14,179 patients with limited-stage SCLC, of whom only $6.1 \%$ underwent surgery. These investigators also demonstrated advancing age and male gender as risk factors for poor survival. They did find a statistical benefit to postoperative RT in patients with $\mathrm{N} 2$ disease $(P=.011) .{ }^{21}$ We are unaware of any studies revealing the prognostic significance of year of diagnosis in surgically resected SCLC. Patient age has been demonstrated to be prognostic of survival in NSCLC. ${ }^{22,23}$ Improved survival could be related to year of diagnosis because of increased incidence of incidentally detected cancers,${ }^{24}$ improvement in radiation techniques, ${ }^{18,25}$ and better staging. ${ }^{26}$ It should be noted that during the years of this investigation, there was no survival improvement

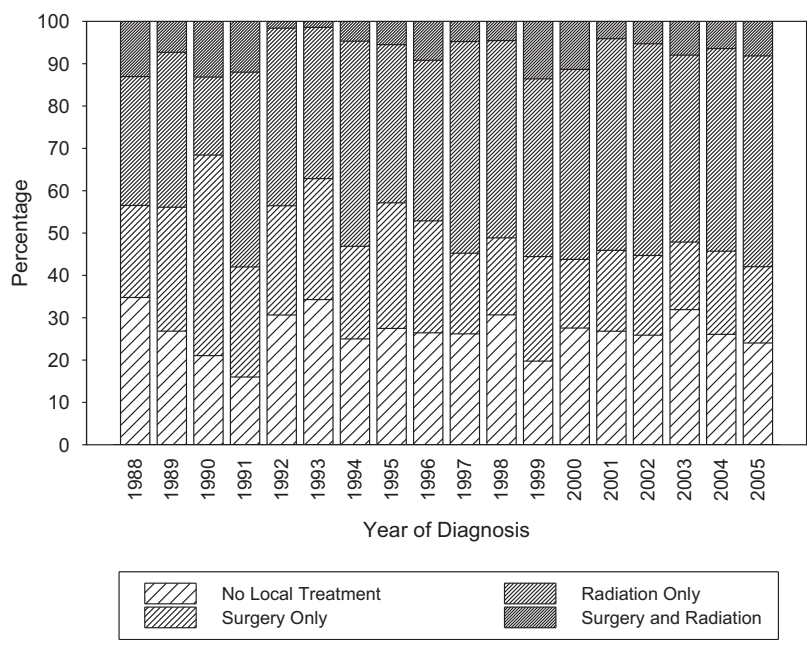

FIGURE 4. Treatment trends for the various therapeutic options over time.

resulting from using chemotherapy in patients with SCLC. $^{27,28}$

There is a recent trend by certain physicians to treat growing or positron emission tomography-positive nodules without biopsy using stereotactic body $\mathrm{RT}^{6-9}$ under the assumption that these metabolically active nodules represent NSCLC. We hoped that we could differentiate early-stage SCLC from early-stage NSCLC on the basis of their presenting characteristics. However, other than early-stage SCLCs being associated with slightly smaller tumor size on presentation, surgically resected stage I SCLC did not differ from NSCLC with regard to patient characteristics or tumor location. Because of the differences in treatment paradigms for stage I SCLCs, which all require chemotherapy and NSCLCs, which do not, we urge a biopsy of such nodules be performed whenever possible.

In addition to limitations regarding RT parameters, the SEER-17 database also does not provide information on performance status, weight loss, patient smoking status, lymphatic or vascular invasion, completeness of resection, lymph node level dissected, preoperative evaluation, receipt of chemotherapy, type of chemotherapeutic agents, and recurrence pattern. Therefore, the observed differences in overall survival and LCSS for patients undergoing surgery may have been due to selection factors (eg, patients with better performance status preferentially undergoing resection).

Of note, during the years of our investigation, the use of RT increased and the use of surgery decreased. This trend began 2 years before publication of a meta-analysis confirming the role of RT in limited-stage disease, ${ }^{29}$ so the reasons for it are not clear.

\section{CONCLUSIONS}

Anatomic lobectomy without the use of adjuvant RT seems to be the optimal local therapy for patients with 
early-stage SCLC. In the absence of mediastinal nodal extension or remote metastatic disease, the addition of adjuvant RT after sublobar resection does not improve overall or cancer-specific survival. RT should be considered for patients who are unfit for any surgical resection.

\section{References}

1. Hann CL, Rudin CM. Management of small-cell lung cancer: incremental changes but hope for the future. Oncology. 2008;22:1486-92.

2. Fox W, Scadding JG. Medical Research Council comparative trial of surgery and radiotherapy for primary treatment of small-celled or oat-celled carcinoma of the bronchus. Ten-year follow-up. Lancet. 1973;2:63-5.

3. Beasley MB, Brambilla E, Travis WD. The 2004 World Health Organization classification of lung tumors. Semin Roentgenol. 2005;40:90-7.

4. Fukuoka M, Furuse K, Saijo N, et al. Randomized trial of cyclophosphamide, doxorubicin, and vincristine versus cisplatin and etoposide versus alternations of these regimens in small-cell lung cancer. J Natl Cancer Inst. 1991;83:855-61.

5. Johnson BE, Crawford J, Downey RJ, et al. Small cell lung cancer clinical practice guidelines in oncology. J Natl Compr Canc Netw. 2006;4:602-22.

6. Takeda A, Sanuki N, Kunieda E, et al. Stereotactic body radiotherapy for primary lung cancer at a dose of 50Gy total in five fractions to periphery of the planning target volume calculated using a superposition algorithm. Int J Radiat Oncol Biol Phys. 2009;73:442-8.

7. Ioue T, Shimizu S, Onimaru R, et al. Clinical outcomes of stereotactic body radiotherapy for small lung lesions clinically diagnosed as primary lung cancer on radiologic examination. Int J Radiat Oncol Biol Phys. 2009;75:683-7. Epub 2009 Feb 21 .

8. Haasbeek CJ, Lagerwaard FJ, de Jaeger K, et al. Stage I lung cancer arising postpneumonectomy. Cancer. 2009;115:587-94.

9. Baumann P, Nyman J, Hoyer M, et al. Stereotactic body radiotherapy for medically inoperable patients with stage I non-small cell lung cancer: a first report of toxicity related to COPD/CVD in a non-randomized prospective phase II study. Radiother Oncol. 2008;88:359-67.

10. Surveillance, Epidemiology, and End Results (SEER) program public-use data (1973-2003), National Cancer Institute, DCCPS, Surveillance Research Statistics Branch. Available at: http://seer.cancer.gov/publicdata/. Accessed February 3, 2009.

11. Surveillance, Epidemiology and End Results (SEER) Program Web Site. Data quality. Available at: http://seer.cancer.gov/about/quality.html. Accessed February 3, 2009.

12. Greene FL, Compton CC, Fritz AG, Shah JP,Winchester DP, eds. Thorax: lung. In: American Joint Committee on Cancer Staging atlas. Part III. Chicago: Springer; 2006:167-76

13. Mantel N. Evaluation of survival data and two new rank order statistics arising in its consideration. Cancer Chemother Rep. 1966;50:163-70.

14. Kaplan ES, Meier P. Non-parametric estimation from incomplete observation. Am Stat Assoc. 1958;53:475-80.

15. Lad T, Piantadosi S, Thomas $P$, et al. A Prospective randomized trial to determine the benefit of surgical resection of residual disease following response of small cell lung cancer to combination chemotherapy. Chest. 1994;106:320-3.

16. Vallières E, Shepherd FA, Crowley J, et al, on Behalf of the International Association for the Study of Lung Cancer International Staging Committee and Participating Institutions. The IASLC Lung Cancer Staging Project: Proposals Regarding the Relevance of TNM in the Pathologic Staging of Small Cell Lung Cancer in the Forthcoming (Seventh) Edition of the TNM Classification for Lung Cancer. J Thorac Oncol. 2009;4:1049-59.

17. Lung Cancer Study Group. Randomized trial of lobectomy versus limited resection for T1N0 non-small cell lung cancer. Ann Thorac Surg. 1995;60: 615-23.

18. Turrissi AT, Kim K, Blum R, et al. Twice-daily compared with once-daily thoracic radiotherapy in limited-stage small-cell lung cancer treated concurrently with cisplatin and etoposide. N Engl J Med. 1999;340:265-71.

19. Shepard FA, Crowley J, Van Houtte P, et al. The International Association for the Study of Lung Cancer Staging Project, lung cancer staging project: proposals regarding the clinical staging of small cell lung cancer in the forthcoming (seventh) edition of the tumor, node, metastasis classification for lung cancer. J Thorac Oncol. 2007;2:1067-76.

20. Lally BE, Geiger AM, Urbanic JJ, et al. Trends in the outcomes for patients with limited stage small cell lung cancer: an analysis of the Surveillance, Epidemiology, and End Results database. Lung Cancer. 2009;64:226-31.
21. Schreiber D, Rineer J, Weedon J, et al. Survival outcomes with the use of surgery in limited-stage small cell lung cancer. Cancer. 2010;116:1350-7.

22. Gail MH, Eagen RT, Feld R, et al. Prognostic factors in patients with resected stage I non-small cell lung cancer, a report from the Lung Cancer Study Group. Cancer. 1984;54:1802-13.

23. Varlotto JM, Recht A, Flickinger JC, et al. Factors associated with local and distal recurrence and survival in patients with resected non-small cell lung cancer. Cancer. 2009;115:1059-69.

24. Henschke CI, Yankelevitz DF, Libby DM, et al. Survival of patients with stage I lung cancer detected on CT Screening. N Engl J Med. 2006;355:1763-71.

25. Graham MV, Purdy JA, Emami B, et al. Clinical dose-volume histogram analysis for pneumonitis after 3D treatment for non-small cell lung cancer (NSCLC). Int J Radiat Oncol Biol Phys. 1999;45:323-9.

26. Pieterman RM, van Putten J, Meuzelaar JJ, et al. Preoperative staging of nonsmall cell lung cancer with positron-emission tomography. $N$ Engl J Med. 2000;343:254-61.

27. Hanna N, Bunn PA, Langer C, et al. Randomized phase III trial comparing irinotecan/cisplatin with etoposide/cisplatin in patients with previously untreated extensive-stage disease small-cell lung cancer. J Clin Oncol. 2006;24:2038-43.

28. Natale RB, Lara PN, Chansky K, et al. A randomized phase III trial comparing irinotecan/cisplatin with etoposide/cisplatin(EP) in patients(pts) with previously untreated extensive stage small cell carcinoma(E-SCLC). Abstract 7512. J Clin Oncol. 2007;26(15S):400S.

29. Pignon JP, Arriagada R, Ihde DC, et al. A meta-analysis of thoracic radiotherapy for small-cell lung cancer. N Engl J Med. 1992;327:1618-24.

\section{Discussion}

Dr Jessica Donington (New York, NY). Thoracic surgery has been discounted for the treatment of SCLC since the 1970s and 1980s because of some randomized trials that lumped all of the limited disease together, probably inappropriately. I think the nice work Eric Vallieres did as part of the International Association for the Study of Lung Cancer Lung Cancer Staging Project showed us that for patients with SCLC without metastatic disease, both the $\mathrm{T}$ stage and the $\mathrm{N}$ stage carry significant prognostic and therapeutic implications. I congratulate you on this excellent work. In looking at that, do we have to look at this as a review of SEER data? I have actually never performed a SEER review, so maybe you can educate me as to some of the things we can and can't take out of this. When we look at the way the patients were staged in this series, I'm assuming that we have both clinical and pathologic stages that we are comparing between the radiation and the surgery groups. Correct?

Dr DeCamp. SEER reports the use of surgery and reports down to the histology of lymph nodes that are sampled, so in the surgery group, obviously there is more precise staging than in the patients with no resection, so they may have only a biopsy, as you saw in Tables 1 and 2.

Dr Donington. So it would be comparing apples and oranges in terms of survival. I guess the same may also be true in that we don't really know about intention to treat and the use of sublobar versus lobectomy or greater in treatment. I'm assuming the sublobars in this series were probably performed in patients who could not tolerate a lobectomy, or we just don't have any information?

Dr DeCamp. We have no knowledge of the surgeon's intent. When we looked at segmentectomy versus wedge resection, the results didn't seem any different. Likewise, if we lumped lobectomy, bilobectomy, and pneumonectomy together, if we tried to split out pneumonectomy, there was no difference in the data, but obviously, because it's retrospective, there is a possibility for selection bias. 
Dr Donington. What kind of information does SEER provide in terms of knowing about the radiation given? I know it doesn't give specifics about field, intensity, and such. Was it all thoracic radiation or was some of this percutaneous coronary intervention?

Dr DeCamp. No, this was all thoracic radiation.

Dr Donington. Do we know about how much prophylactic cranial irradiation was given to these patients? We know that significantly affects survival in this population.

Dr DeCamp. No, we don't.

Dr Donington. Your work actually coincides with several other reviews of the SEER database looking at surgical resection for SCLC. The 3 reviews, yours, one from Yale, and one from SUNY Downstate, have similar take-home messages: There really is an important role for surgery. Some of the take-home message regarding the use of adjuvant RT, though, was different. Can you address the fact that those 2 studies actually found no impact from the use of adjuvant RT, or in the SUNY review, a similar kind of pattern to what we see in NSCLC, where with increasing nodal status, perhaps adjuvant radiation makes sense.

Dr DeCamp. The difference among the 3 SEER reviews is that we restricted ourselves to early stage, not limited stage, as the oncologists like to speak of it, but T1N0, T2N0, and N1 cases. The SUNY Downstate review, which is primarily written by radiotherapists, makes the analogy to the PORT meta-analysis in NSCLC; in that analysis, there was a detriment when radiation was used in stage I disease, although it included some old radiation from the 1970s, which may have been more detrimental, no benefit for stage II, but a small survival benefit in stage III disease. We have no patients with stage III in our series, and we are doing this from the perspective of surgeons and clinicians.

Dr Donington. Did you see any difference in survival with radiation between those with stage I and those with stage II?

Dr DeCamp. No, we didn't. It seems that the patients derive no additional benefit from the addition of radiation after surgery. As you see from the curves, the $P$ values are between .2 and .5 , so they are statistically similar and clearly inferior to any of the surgical arms, which was surgery alone.

Dr Donington. My last question is speculative in nature. Do you have any insight as to why we saw that fairly dramatic increase in the cases of small cell in 2004 and 2005?

Dr DeCamp. I found that kind of interesting in an era when half the American smoking population quit smoking in the last 30 years. So we have fewer active smokers. Small cell tends to be a disease of active smokers. I think a lot of it has to do with the increasing utility of computed tomography scanning and finding more tumors earlier, and that may be a prediagnosis or an overdiagnosis bias, but as we think about NSCLC and SCLC, people die of these diseases; they don't die with these diseases. So I have a hard time accepting the overdiagnosis bias argument. I don't know why we're seeing so many more small cell cases, but it was curious and consistent in the last 4 or 5 years of this review.

Dr Donington. I think it makes your article ever more important.

Dr Raja Flores (New York, NY). Mac, I commend you on doing a great job with the limited data that are presented in SEER. I think this does add support to thoracic surgeons performing surgical resection for SCLC. I have a quick question. With these patients who underwent surgery, do you have any idea of the number of patients who underwent preoperative mediastinoscopy? Is that recorded at all in the SEER database?

Dr DeCamp. No. You just get a report of lymph nodes. You don't get a report of how they were obtained. So you get mediastinal or hilar lymph nodes. We can assume the hilar nodes were not at mediastinoscopy.

Dr Mark Iannettoni (Iowa City, Iowa). Mac, I enjoyed your article. This is the third time we've heard that surgery has value for SCLC. In 1985 John Meyer presented it. Tom Shields has presented it in the past. Why do you think we just haven't gotten through to people yet that this is a valuable entity?

Dr DeCamp. I can only speculate that there are not multidisciplinary teams evaluating patients, and if you don't see them and you're not involved, you won't be at the table making the treatment decisions. The SUNY Downstate review, which was primarily written by radiation oncologists, and the current article will bring this more into the consciousness, and with more multidisciplinary evaluations being performed around the country, we'll be back at the table.

Dr Iannettoni. I think that's the point. We need to get out of the operating room and get to some of these conferences.

Dr Joe Putnam (Nashville, Tenn). I enjoyed the article and was curious if this may reflect a more nihilistic approach of other specialists, such as medical or radiation oncology. These specialists see patients with more advanced stage SCLC and may be reluctant to have smaller SCLCs treated with resection as an initial treatment modality.

The question I have is about diagnosis. Were you able to determine the percentage of patients who had a diagnosis preoperatively versus postoperatively? Many of these patients may have a diagnosis made as a consequence of operations for a solitary pulmonary nodule.

Dr DeCamp. From the SEER data, I know of no way to discriminate or answer that question specifically.

Dr Putnam. From your data, the change over time may have resulted in the increased use of computed tomography and other diagnostic studies, as well as more availability of preoperative needle diagnosis. In those patients who had a diagnosis of SCLC made with needle diagnosis, the surgeon may never see them, even if they have limited and resectable disease. It may be helpful to partner with our radiologists in addition to our medical oncologists to understand that these patients can be seen by a surgeon and effectively treated.

Dr Stephen Yang (Baltimore, $M d$ ). As a follow-up to this, maybe we can have a take-home message from all these article. I'll sort of plug Malcolm Brock's article from 1997 from our institution, in which he showed that with platinum-based therapy these days, surgery plus chemotherapy affords a 75\% 5-year survival for stage I disease. The take-home message now: The patient comes in, small cell, preoperative diagnosis. What do you tell the tumor board? In the second scenario, as Bill alluded to, the patient has a lobectomy for a solitary nodule, and it comes back a small cell. What is the decision point after that?

Dr DeCamp. Thank you, Steve. I have to take my hat off to Dave Sugarbaker if he's in the audience because he taught me that you evaluate a solitary pulmonary nodule, and if it is small cell and the mediastinum is negative, take it out. You do the lobectomy. Treat it like you do lung cancer. If this person clearly needs 
systemic therapy, you know, that's the greatest risk. If I've done a mediastinoscopy and lobectomy on the basis of what we learned this morning or a good mediastinal sampling or radical mediastinal lymphadenectomy, as long as I've assessed the mediastinum, that patient has had adequate local therapy, and the patient needs systemic therapy and doesn't benefit from radiation therapy.

Dr Yang. Just one more comment. We have put in an American College of Surgeons Oncology Group protocol for small cell. I hope it will be engaged in about 1 year. We are going to be looking at this prospectively for patients who do have small cell. They do receive chemotherapy postoperatively. But I think the more important thing will be looking at the translational material, getting the blood, sputum, and tumor sample so we can learn more about the disease, which we haven't had in the past.

Dr Robert Cerfolio (Birmingham, Ala). So, Mac, I'm in the operating room. I wedge it out. They call back with small cell. I take all the N2 nodes and send those for frozen-section, and 2 of them are positive, microscopic disease. Do I do a lobe or don't I?

Dr DeCamp. I don't think you need to do a lobe.
Dr Jack Roth (Houston, Tex). It's not unusual to see mixed histologies with both small cell and non-small cell components. Given the time frame of this study and the radiation doses that were probably used, radiation was likely more effective on the small cell component and less effective on the non-small cell component. What percentage of these patients had mixed histology, and how accurate was your histologic evaluation for these patients?

Dr DeCamp. Well, anybody who has worked with SEER or any other database knows that they really want discrete fields. So patients who were entered were forced to be diagnosed with a discrete classification. So within non-small cell, they can be adeno- or squamous, but when I looked at the data fields, I didn't see the option of mixed tumors. We went through and there are a few more unusual forms, fusiform cell and things like that for small cell. We eliminated the "intermediate cell" from our analysis because I thought those were cases on the fence. I think your point is well taken. Especially if it's a needle diagnosis for small cell and the patient doesn't respond the way you expect, I think those are likely mixed tumors. 